\title{
Productivity management in the South African civil construction industry - factors affecting construction productivity
}

\author{
M Bierman, A Marnewick, J H C Pretorius
}

Labour productivity in South Africa is at one of its lowest levels. During 2014 the civil construction industry contributed only 3.5\% to the GDP of South Africa. It is faced with challenges such as an industry environment that is increasingly competitive, and organisations in the civil industry that experience financial difficulties, such as low profit margins. An industryspecific survey, using a questionnaire, was conducted to ascertain the perceptions of industry professionals regarding factors which have an impact on productivity. A literature study was done to identify the factors that have an impact on construction productivity, based on a global perspective. From the literature study, 12 studies were identified, and a benchmark was set with which to compare the findings of the research questionnaire.

To obtain the relevant information through the questionnaire, a selective sampling process was used, as the focus of the research required a specific group of individuals who were involved in the management of projects in the civil construction industry. Two civil engineering organisations, the South African Forum of Civil Engineering Contractors and the South African Institution of Civil Engineering, were contacted to assist with the distribution of the questionnaire. The questionnaire consisted of 51 factors which the industry professionals had to rate, based on their experience. These factors had to be rated with the use of a 0-4 Likert scale, based on two specific questions: (1) What impact does the factor have on construction productivity? (2) What is the frequency of occurrence of the factor?

A total of 40 questionnaires were completed by the industry professionals. Thereafter the ranking of the factors was calculated with the use of the relative importance index.

\section{INTRODUCTION}

Labour productivity in South Africa is at its lowest in 46 years (Naicker 2014). More alarmingly, South Africa, when compared to its emerging market competitors, is less efficient, and labour productivity here is one of the lowest in the developing world. This contributes to a negative outlook for the economy and the wellbeing of its citizens. The Office for National Statistics in the UK (ONS 2007) states that an increase in productivity is "the key determinant of economic growth".

The civil construction industry contributed only 3.5\% to South Africa's GDP during 2014. It is confronted with an industry environment that is increasingly competitive and that experiences perpetually changing conditions (SAFCEC 2014; Langston 2012).

The industry, by nature, is highly labourintensive, and employs a significant number of unskilled and semi-skilled workers from the communities which are located close to the civil construction projects. The aim of this research, therefore, was to identify the factors which have an impact on the global productivity of the South African civil construction industry and to compare them with international trends. The paper considers a global view of productivity, and not just labour productivity.

\section{FACTORS IMPACTING ON CONSTRUCTION PRODUCTIVITY}

Before productivity management can be considered, the concept and definition of both productivity and management have to be understood. Productivity is defined by the Oxford dictionary (2014) as "the state or quality of being productive", and in a general sense is defined as a measure of the output compared to the input. A common mathematical expression for productivity is the output divided by the input (Productivity = Output/Input) (Liou \& Borcherding 1986). From this expression it is clear that productivity could

\section{JOURNAL OF THE SOUTH AFRICAN INSTITUTION OF CIVIL ENGINEERING}

Vol 58 No 3, September 2016, Pages 37-44, Paper 1253

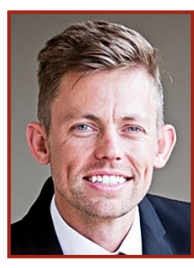

MARIUS BIERMAN is a graduate member of the South African Institution of Civil Engineering (SAICE). He received his Bachelor's in Civil Engineering (2008) and his Master's (cum laude) in Engineering Management (2015), both at the University of Johannesburg. He is currently employed as a civil engineer at Group Five Civil Engineering where he is involved with construction management of large-scale civil projects.

Contact details:

17 Riethaan Avenue

The Reeds

Centurion

South Africa

0157

T: +27829292679

E: marius.bierman@gmail.com

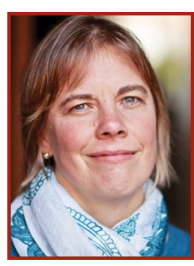

DR ANNLIZÉ MARNEWICK Pr Eng holds a D Ing and $M$ Ing in Engineering Management, a B Ing Electrical and Electronic Engineering, as well as a BSc Hons in Applied Mathematics. She is currently a senior lecturer at the Postgraduate School of Engineering Management, University of Johannesburg, where she focuses on the supervision of research Master's and PhD

students. Before joining academia, she worked in the industry for 14 years, specialising in requirements engineering.

\section{Contact details:}

Postgraduate School of Engineering Management

Faculty of Engineering and the Built Environment

University of Johannesburg

PO Box 524

Auckland Park

2006

South Africa

T:+27 115591735

E:amarnewick@uj.ac.za

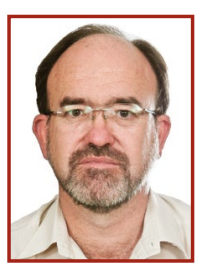

PROF JAN-HARM PRETORIUS Pr Eng (SMIEEE, FSAIEEE) holds a BSc Hons (Electrotechnics), an MSc (Pulse Power and Laser Physics) and M Ing and D Ing degrees in Electrical and Electronic Engineering. He was a senior consulting enginee at the South African Atomic Energy Corporation previously, and technology manager at the Satellite Applications Centre at the CSIR. Currently he is Head of the Postgraduate School of Engineering Management at the University of Johannesburg. He is involved in measurement and verification of energy saving for Eskom and NamPower. He has authored 120 research papers and supervised over $20 \mathrm{PhD}$ and 120 Master's students.

Contact details:

Postgraduate School of Engineering Management

Faculty of Engineering and the Built Environment

University of Johannesburg

PO Box 524

Auckland Park

2006

South Africa

T: +27115591730

E: jhcpretorius@ui.ac.za 


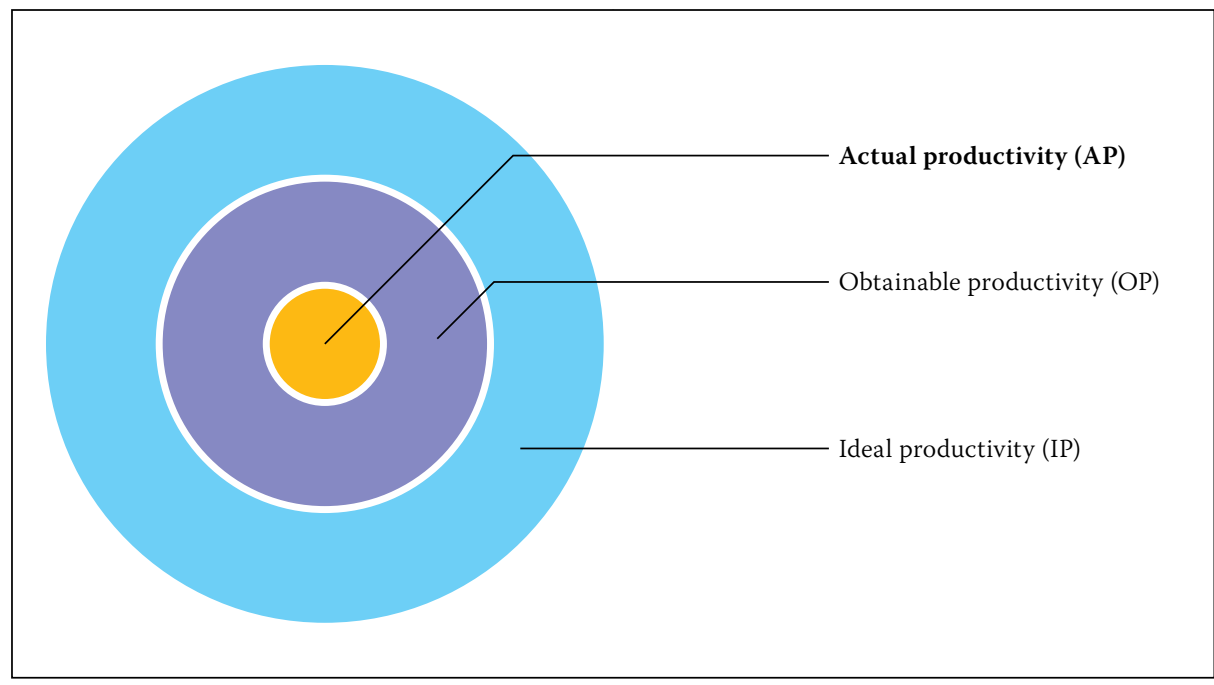

Figure 1 Actual productivity (Kim et al 2011)

improve if either the output increases with the input staying constant, or if the input decreases and the output remains constant. Management is defined by the Oxford dictionary (2014) as "the process of dealing with or controlling things or people". Productivity management is therefore the process of managing processes and people with the focus on the state of being productive.

Kim et al (2011) assume that there are two levels of productivity. On the one hand, they mention productivity that can be achieved in ideal situations, which they call 'ideal productivity' (IP), and on the other hand, realistic productivity which they call 'obtainable productivity' (OP). The productivity that is actually achieved is 'actual productivity' (AP). They further define a reduction factor which represents a factor that inhibits the attainment of a complete IP value. In other words, actual productivity is ideal productivity from which the reduction factor is subtracted. Figure 1 is a graphical representation of the relationship between ideal, obtainable and actual productivity. The aim of improving productivity lies in the actual productivity sector.

Furthermore, Kim et al (2011) distinguish between different types of reduction factors, which they call the controlled (C_RF) and uncontrolled (UC_RF) reduction factors. In short, the uncontrolled reduction factors have an impact on ideal productivity, resulting in OP = IP - UC_RF. Optimum productivity is subsequently impacted by the controlled reduction factor so that actual productivity is defined as AP $=\mathrm{OP}-\mathrm{C} \_\mathrm{RF}$. while some factors can remain constant; these factors are called variable and invariable, respectively. Figure 2 indicates the relationship of the factors in a matrix format.

The ONS Productivity Handbook (ONS 2007) states that productivity can be seen Factors can vary during the project life cycle,

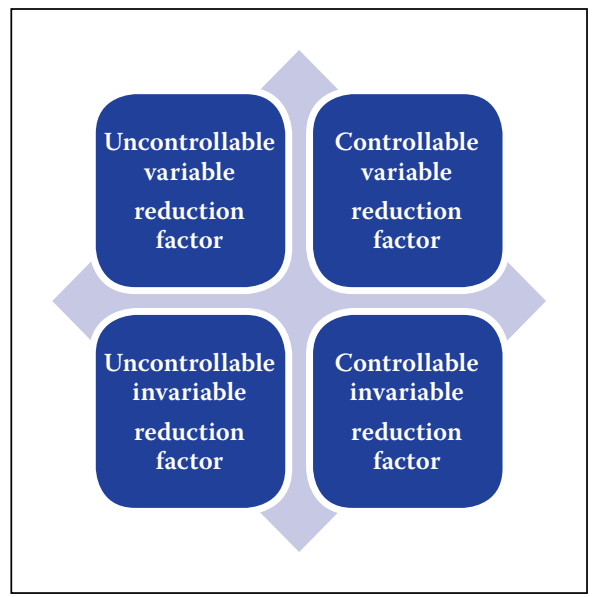

Figure 2 Classification of factors based on controllability and variability (Kim et al 2011)

as the ratio between input and output, and that productivity can be increased through the reduction in input. The labour force is the most common input that is changed to obtain the desired productivity. Unfortunately, this definition of productivity is not suitable in South Africa due to the country's socioeconomic climate where unemployment is a major concern. Moreover, productivity has an impact on several aspects, such as the economy and society in general, and is seen as "the key determinant of economic growth" (ONS 2007). It is therefore critical to identify the factors that have an impact and to fully understand how they can be managed to minimise their effect on construction productivity.

The South African civil construction industry is subjected to fluctuating conditions, such as low turnover, unemployment, erratic tender activities and the liquidation of construction companies (SAFCEC 2014).

Table 1 Factors affecting construction productivity ranked by various authors

\begin{tabular}{|c|c|c|c|c|c|c|c|}
\hline Authors & Country & Labour & Management & $\begin{array}{c}\text { Site } \\
\text { characteristics }\end{array}$ & Weather & Consultant & $\begin{array}{c}\text { Tools \& } \\
\text { equipment }\end{array}$ \\
\hline Abdul Kadir et al (2005) & Malaysia & & 4 & & & 2 & \\
\hline Alinaitwe et al (2007) & Uganda & 2 & 3 & & 1 & 1 & 2 \\
\hline Duryev and Mbachu (2011) & New Zealand & 1 & 5 & 1 & & 1 & \\
\hline El-Gohary and Aziz (2014) & Egypt & 5 & 7 & 1 & 1 & 1 & \\
\hline Enshassi et al (2007) & Gaza Strip & 1 & 3 & & & 1 & \\
\hline Horner et al (1989) & UK & 2 & 7 & 1 & & 2 & 1 \\
\hline Hughes and Thorpe (2014) & Australia & 2 & 10 & & & 1 & 2 \\
\hline Jarkas and Bitar (2012) & Kuwait & & 2 & & & 3 & \\
\hline Kaming et al (1997) & Indonesia & 1 & 3 & & & & 1 \\
\hline Lim and Alum (1995) & Singapore & 2 & 3 & & 1 & & \\
\hline Makulsawatudom et al (2004) & Thailand & 1 & 6 & & & 2 & 1 \\
\hline Zakeri (1996) & Iran & & 1 & & 1 & 1 & 2 \\
\hline \multicolumn{2}{|l|}{ Total } & 17 & 54 & 3 & 4 & 15 & 9 \\
\hline
\end{tabular}


Table 2 Benchmark of top ten factors obtained from literature study

\begin{tabular}{|l|c|c|}
\hline \multicolumn{1}{|c|}{ Factor } & Category & Ranking \\
\hline Material shortage & Management & 2 \\
\hline Labour experience & Labour & 3 \\
\hline Incompetent supervisor & Management & 4 \\
\hline Method of working & Management & 5 \\
\hline Late issue of drawings & Consultant & 7 \\
\hline Poor communication & Management & 8 \\
\hline Unforeseen events & Management & 9 \\
\hline Poor site layout & Management & 10 \\
\hline Constructability & Consultant & 2 \\
\hline Rework & Management & \multicolumn{2}{|c|}{} \\
\hline
\end{tabular}

Table 3 Likert scale used in the questionnaire

\begin{tabular}{|l|c|c|c|c|c|}
\hline \multirow{2}{*}{$\begin{array}{c}\text { Question } \\
\text { category }\end{array}$} & $\mathbf{0}$ & $\mathbf{1}$ & $\mathbf{5}$ & $\mathbf{3}$ & $\mathbf{4}$ \\
\cline { 2 - 6 } & No opinion & No impact & Slight impact & $\begin{array}{c}\text { Considerable } \\
\text { impact }\end{array}$ & Great impact \\
\hline $\begin{array}{l}\text { Frequency of } \\
\text { impcurrence }\end{array}$ & Never & Seldom & Occasionally & $\begin{array}{c}\text { To a } \\
\text { considerable } \\
\text { degree }\end{array}$ & Almost always \\
\hline
\end{tabular}

It is therefore important to identify the factors which have an impact on construction productivity, with the intention of managing their effects.

A literature study was conducted with the purpose of identifying factors that have an impact on construction industries from a global perspective. Twelve studies from the literature were identified that support the research in this article, as indicated in Table 1. The authors studied the impact that certain factors (as identified by industry professionals) have on construction productivity The factors were grouped into six main categories, i.e. management, labour, consultants, tools/equipment, weather and site characteristics. These factors were categorised to accommodate the factors in the literature, with the aim of setting a benchmark. Three main categories that predominantly occurred in the literature, and which have a perceived impact on construction productivity (as indicated in Table 1), can be identified from the results. The management category is first with the highest number of factors at 54, the labour category is second with 17 factors, and the consultant category is third with 15 . These categories were used to create the research questionnaire.

\section{BENCHMARK}

The top ten factors of the various authors were combined to set a benchmark that was used to compare the findings of the research questionnaire. The factors were selected according to the findings of the authors, as illustrated in Table 2. They were compared with one another (in the same ranking) and the most dominant factor was selected to represent the specific ranking.

The top ten factors in Table 2 are consistent with the findings in Table 1. There are three main categories, i.e. management, labour and consultants. Management is the dominant category in the list with seven of the ten rankings, which account for $70 \%$ of the factors. Consultants constitute $20 \%$ of the factors, while the labour category constitutes only $10 \%$ of the factors.

\section{RESEARCH METHODOLOGY}

The selection of factors was guided by the research that was conducted by the various researchers as per Table 1, as well as the productivity factors that were identified by Arditi (1985). This was done as it considered both the site and head office contribution to productivity. The scope of the study only included the construction phase of the project (start-up to completion and handover); it did not include the inception, design and feasibility study stages of the project. Moreover, the productivity measurements do not consider the impact of the factors on various stages during the construction phase. A holistic approach was adopted to focus the attention of the participants on the overall construction project and not parts of it.

\section{Selection and categorisation of factors}

The selection criteria for the factors that were used in the research questionnaire were based on the literature study. Six categories were derived from the literature study, namely management, labour, consultants, tools/ equipment, weather and site characteristics. This was done to compare the results from the various authors in the literature study.

\section{Definition of questions and rating scale}

The factors in the questionnaire were rated according to a Likert scale, and two categories of questions were asked for each of the factors. The Likert scale was utilised in this research as it is one of the simplest and most widely used scales for research purposes (Othman et al 2005). Moreover, as indicated in Table 1, the authors (from the literature study) had also used the Likert scale to conduct their research.

The two questions that were posed to the industry professionals were about, firstly, the perceived impact the factor had on construction productivity, and secondly, how frequently the factor occurred during the project life cycle. A $0-4$ Likert scale was used, as indicated in Table 3; the scale for the frequency of occurrence was altered to provide a suitable scale to rate the frequency.

\section{Identification of target audience}

Expert sampling was used, as the focus of the research required a specific group of individuals who were involved in the management of projects in the civil construction industry, such as project managers, site agents, engineers, contract directors and managing directors (Salem \& Zimmer 2005).

Two industry-relevant organisations were contacted to assist with the distribution of the questionnaire. The first was the South African Forum of Civil Engineering Contractors (SAFCEC), which has a membership of 450 civil construction companies. The second was the South African Institution of Civil Engineering (SAICE), which has 1460 members in its project management and construction division. The sample distribution in this research only included the industry professionals who were involved in the management of civil construction projects. This therefore excluded design engineers, architects or other industry professionals who operate in the construction industry, but who are not directly involved in the management of a project. Further research should be conducted that 
would include all industry professionals through the complete project life cycle.

\section{Compilation and distribution of questionnaire}

The questionnaire was created using an online survey platform called SurveyMonkey. The online application allowed the participants to access the questionnaire irrespective of their geographical location, and to complete the questionnaire in their own time. A link to the online survey was generated and sent to SAFCEC and SAICE for distribution. The responses to the questionnaire were collected and summarised by SurveyMonkey, generating a summary table with the findings. The data was extracted from the summary table and collated in Microsoft Excel, in which the analysis of the data and the subsequent charts were generated.

\section{Analysis of results}

The relative importance index (Rii) is used to grade results in terms of severity, and allows different factors to be compared with one another. It was used to compare the scoring of the factors that were captured in the questionnaire by using the Likert scale. The formula for Rii is indicated in Equation 1.

$R i i=\frac{\sum_{r=0}^{4} r * n_{r}}{4 N}$

where:

$r=$ rating according to Likert scale (0-4)

$n_{r}=$ number of results of $r$ (Likert scale)

$N=$ number of questions answered in questionnaire

The modified relative importance index (MRii), as used in this research, is defined as the average of two Rii values which have a

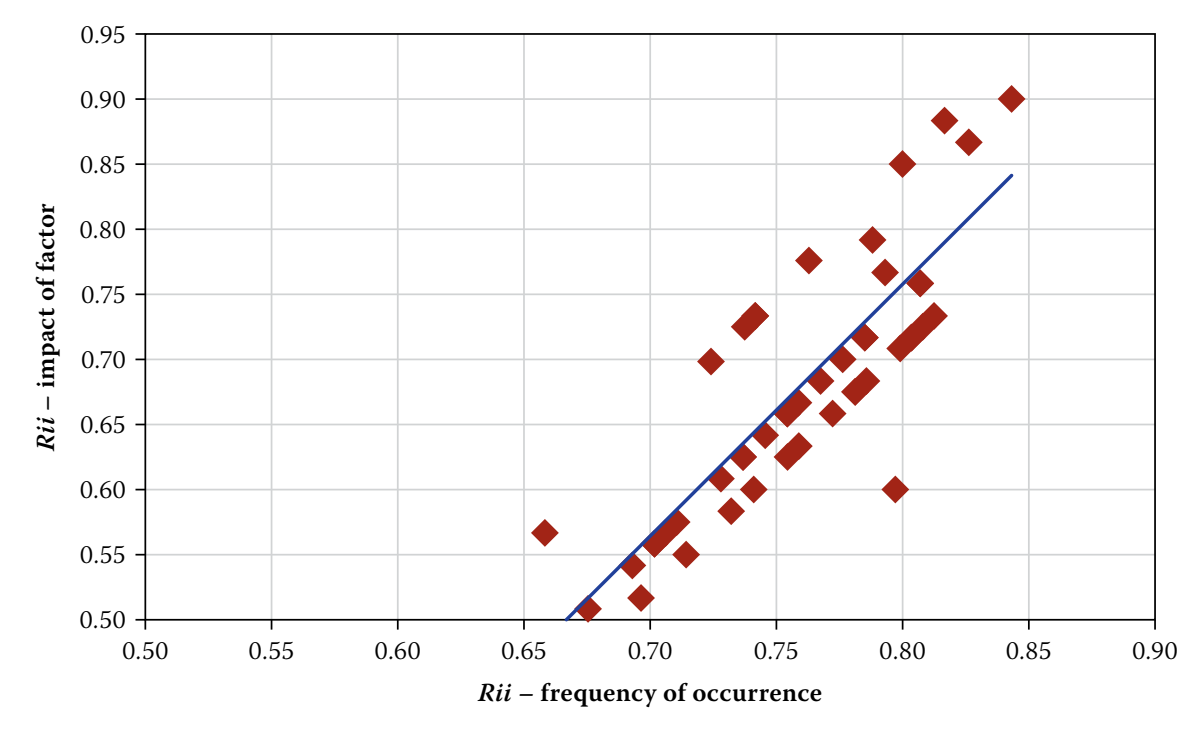

\section{Figure 3 Correlation between frequency and impact of factors}

linear relationship, as indicated in Equation 2. El-Gohary (El-Gohary \& Aziz 2014) modified the Rii to calculate the relative importance index for categories based on years of experience, and calculated the category index by taking the average of Rii for each factor.

$M R i i=\frac{\text { Rii of the impact }+ \text { Rii of the frequency }}{2}$

The first stage in analysing the data entailed calculating the Rii for each of the factors.

This was done for the two main categories of questions. An Excel spreadsheet was used to capture and analyse the data of each of the factors. The second stage entailed establishing if there was a linear relationship between the categories of questions, with the aim of validating the use of the MRii (as identified in Equation 2). Bivariate analysis was used to ascertain the relationship. The Rii values were plotted on an XY chart, as shown in Figure 3.
The Y values were selected as the Rii of the impact, and the $\mathrm{X}$ values were the $R i i$ frequency of occurrence. The correlation between the impact and frequency was calculated, and the Pearson's $r$ correlation value was at 0.838 , with significance at the 0.01 level (two-tailed). This value is close to 1 and thus indicates a strong linear relationship between the impact and frequency (Liu et al 2011). In conclusion, the MRii can be calculated where the relationship between the impact and frequency is accepted as being linear. The analysis of the results and the subsequent comparison with the benchmark were based on the Rii ranking and not on MRii; this was done to ensure that the results from the questionnaire could be compared directly with the benchmark. The MRii was adopted to introduce a new avenue of thought in which the occurrence frequency of the factors had an additional influence on the impact.

Table 4 Combined top ten findings of questionnaire listed under Rii of impact, frequency and MRii, sorted based on MRii

\begin{tabular}{|c|c|c|c|c|c|}
\hline \multirow[b]{2}{*}{ Factor (combined) } & \multirow[b]{2}{*}{ Category } & \multirow{2}{*}{$\begin{array}{c}\text { Ranking based } \\
\text { on } M R i i\end{array}$} & \multicolumn{3}{|c|}{ Relative importance index (Rii) } \\
\hline & & & $\begin{array}{l}\text { Impact of } \\
\text { factor (A) }\end{array}$ & $\begin{array}{c}\text { Frequency of } \\
\text { occurrence (B) }\end{array}$ & $\begin{array}{l}\text { MRii (average } \\
\text { of A \& B) }\end{array}$ \\
\hline Late issue of drawings to contractor & Consultant & 1 & 0.900 & 0.843 & 0.872 \\
\hline Illegal strike action by project labour force & Labour & 2 & 0.883 & 0.817 & 0.850 \\
\hline Delayed reply on RFI (request for information) & Consultant & 3 & 0.867 & 0.826 & 0.846 \\
\hline Late issue of specifications and information to contractor & Consultant & 4 & 0.867 & 0.826 & 0.846 \\
\hline Civil unrest in vicinity of project & Labour & 5 & 0.850 & 0.800 & 0.825 \\
\hline Labour union strike (irrespective of union) & Labour & 6 & 0.850 & 0.800 & 0.825 \\
\hline Delayed inspection by consultant & Consultant & 7 & 0.792 & 0.788 & 0.790 \\
\hline Management skills of foreman & Management & 8 & 0.758 & 0.807 & 0.783 \\
\hline Poor communication between site management and labour force & Management & 9 & 0.758 & 0.807 & 0.783 \\
\hline Complexity of design (constructability) & Consultant & 10 & 0.767 & 0.793 & 0.780 \\
\hline
\end{tabular}




\section{Analysis of findings}

In total, 40 participants (construction management industry professionals) took part in the survey. The combined results, as shown in Table 4, indicate the top ten factors that were perceived to have an impact on construction productivity. However, it is not sufficient to view the results in isolation. The impact, as well as the frequency of occurrence, should be considered. The Rii was calculated for both the impact of factor and frequency of occurrence. Furthermore, the $M R i i$ was obtained by calculating the average Rii of the two Rii values. Figure 4 indicates the number of factors (based on Rii) for each of the six categories.

The results from Table 4 and Figure 4 indicate the following:

- Impact of the factor: The top ten factors fall into only three of the six categories (management, consultant and labour). The main category that is perceived to have an impact on productivity is 'management'.

- Frequency of occurrence: The results are spread in more categories for frequency than impact (five of the six categories). This, however, only indicates the frequency of occurrence and is not a useful measure on its own, and as such was used to calculate the MRii.

- MRii: The modified value was obtained as stated above and should be compared to the impact of the factor. The modification to the Rii caused a slight increase in the number of factors that were in the management category, while a reduction by almost half in the labour category was also noted. The remainder fell into the site condition and tools/ equipment categories.

The results of the study were combined in Figure 5 (see Table 5 for complete list of ranked factors) to represent the relationship between the different Rii values. The Rii values for the impact and frequency seem to fluctuate, and the MRii is a relatively smooth line (this is due to the fact that findings were ranked based on the MRii), as shown in Figure 5. The first six factors had a higher Rii rating for impact than for frequency. The Rii values from factors 7 to 51 indicate trends where the Rii for frequency is higher than the Rii for impact.

The inclusion of the frequency of occurrence had an interesting result on the ranking of factors. Factors with a low perceived impact had a high frequency of occurrence and would be ranked higher than a factor with a high impact but low frequency. For example, factor 20 (Breakdown of plant) had a lower Rii (impact) than factor 21 (Availability of

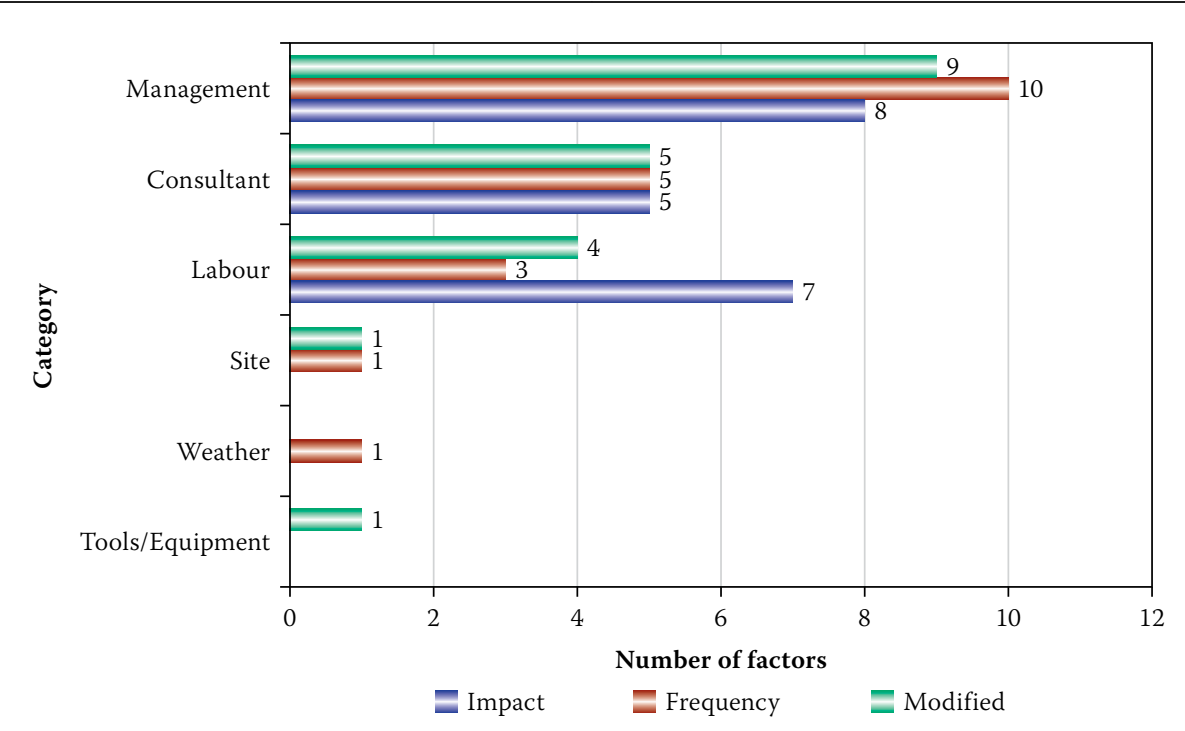

Figure 4 Comparison between the three different Rii values for the six categories of factors

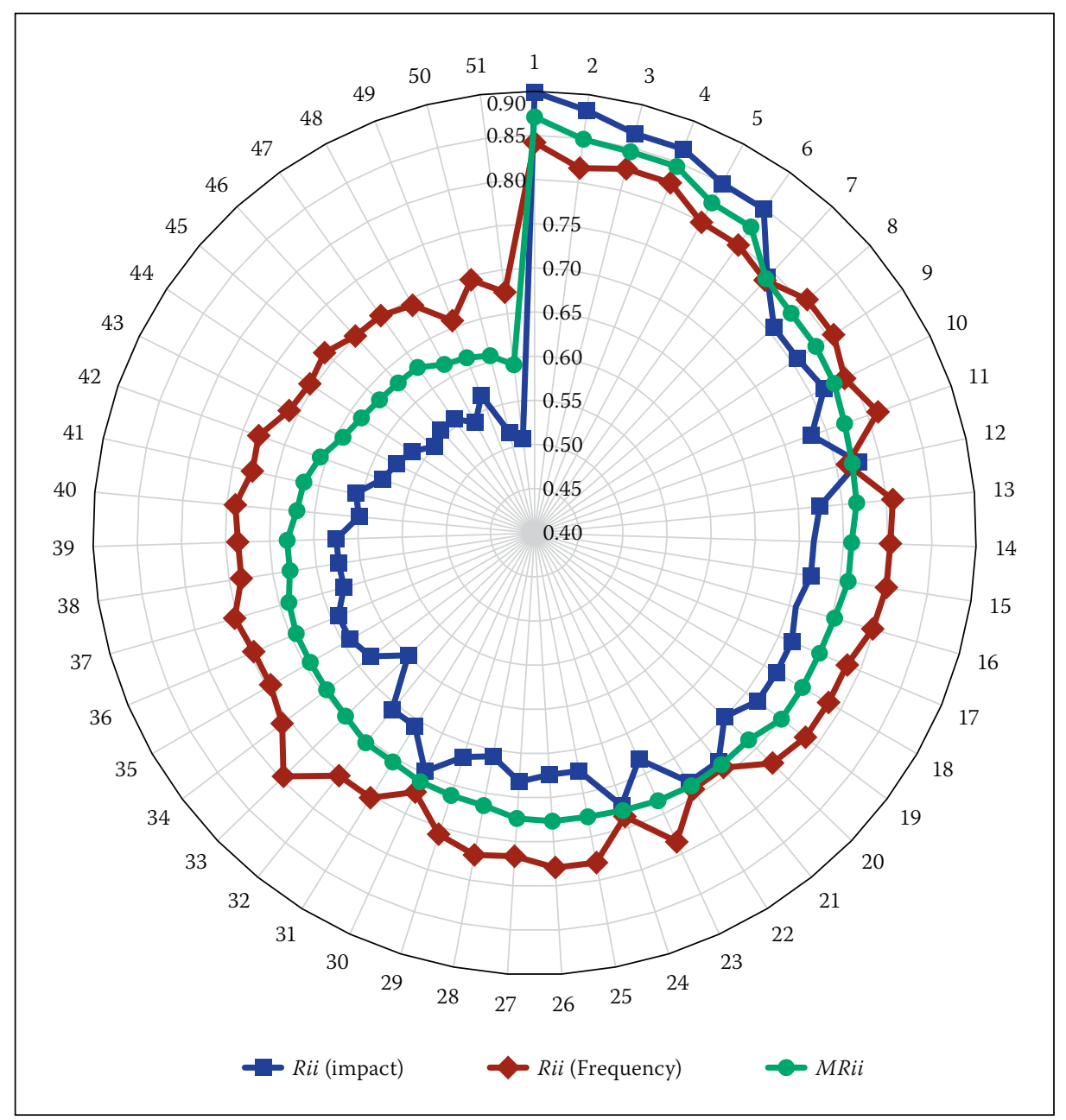

Figure 5 Graphical representation of the findings - a total of 51 factors ranked based on MRii (refer to Table 6 for details of each factor)

skilled labour ...'), which means that the availability of labour should be ranked higher (see Table 5). The frequency influenced the ranking such that the breakdown of plant was ranked higher than the availability of skilled labour. This ties in with the approach of the study whereby a holistic approach was adopted to evaluate the effect of factors on productivity.
The ranking of the factor category was done by calculating the average of the Rii of all the factors in the category. The average Rii values were compared to one another and ranked accordingly. Table 6 indicates that the top three factors are in line with the findings of the literature study. However, the highest ranked factor category is consultants, whereas the literature ranked management as the highest. 
Table 5 Ranking of the 51 factors, grouped according to categories of factors (refer to Figure 5 for graphical comparison between Rii $_{(\text {(impact)' }}$ Rii $_{(\text {frequency) }}$, and MRii)

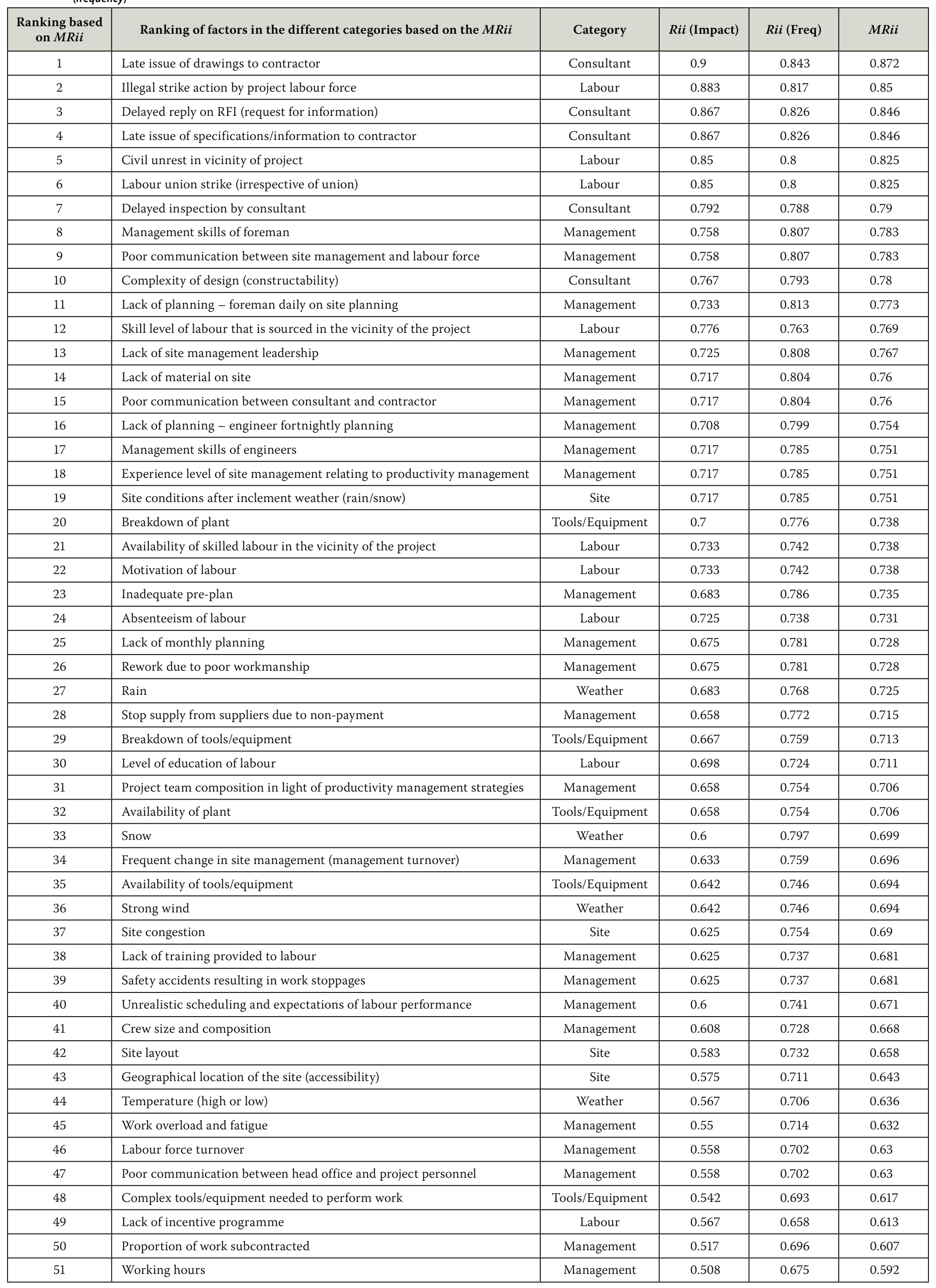


Table 6 Ranking of the six categories of factors

\begin{tabular}{|l|c|c|c|c|}
\hline Factor category & $\begin{array}{c}\text { Average of } \mathbf{R i i} \\
\text { (impact) }\end{array}$ & $\begin{array}{c}\text { Average of } \mathbf{R i i} \\
\text { (frequency) }\end{array}$ & Average of MRii & Factor category \\
\hline Consultant & 0.838 & 0.815 & 0.827 & 1 \\
\hline Labour & 0.757 & 0.754 & 0.755 & 2 \\
\hline Management & 0.653 & 0.762 & 0.708 & 4 \\
\hline Site conditions & 0.625 & 0.746 & 0.685 & 5 \\
\hline Tools/equipment & 0.642 & 0.746 & 0.694 & 6 \\
\hline Weather & 0.623 & 0.754 & 0.689 & \\
\hline Average & 0.684 & 0.762 & 0.723 & \\
\hline
\end{tabular}

\section{COMPARING FINDINGS WITH BENCHMARK}

The results from the questionnaire and the benchmark are combined in Table 7 in order to compare the findings. The results of the Rii (impact) were selected to be compared to the benchmark, since the literature study focused only on impact and not on frequency as identified in this research. In Table 7 there are seven factors that are classified as management, one as labour and two as consultant-related factors. This is in stark contrast to the finding in the questionnaire where the majority of the factors, a total of five, pertained to consultant engineers. The accountability of construction management professionals is brought into question when viewing the results of the questionnaire, as it is apparent that the consulting engineers are blamed for poor productivity. This is a skewed result, as the participants of the questionnaire were only involved in the management of construction projects and not in the design of the project. The inclusion of design engineers in the target audience could have provided a different result, but this paper only considers individuals who are directly involved in the construction management of a project.

A variance column is included in Table 7, which indicates the movement in terms of the ranking of the factors. Only one factor stayed ranked in the same position, i.e. constructability, which is ranked ninth. Furthermore, six factors do not have a match in the list of top ten factors and are marked as 'NA'. The variance was calculated by evaluating the movement of column B (results from questionnaire) in relation to column A (benchmark).

Labour experience and incompetent supervisors moved down six and seven places respectively, compared to the findings in the questionnaire, whereas the late issue of drawings moved up four places. The discrepancy in the factors could mean that the civil construction industry in South Africa is faced with a different set of problems from those which are identified in the global civil construction industry.

The results further indicate that South Africa has a unique set of factors which impact on construction productivity. For instance, the occurrence of labour force strikes (irrespective of legality) is more prominent in South Africa than globally (Odendaal 2014). The recent strike in the mining industry is one example of the challenges South Africans face in terms of labour relations. The construction industry contributed $13.5 \%$ of the working days lost within the South African market due to labour strikes as per the annual industrial action report (Department of Labour 2013). The lack of skilled professionals compounds the issue even further. An article in Engineering News stated that the engineering skills shortage hampers the growth of South Africa (Cloete 2013). The government has, however, tried to solve the problem by introducing the critical skills work visa (Republic of South Africa 2014). The impact of this initiative on the industry and the perceptions of the industry professionals should be investigated in further studies.

\section{RESEARCH LIMITATIONS}

The research focused on a large industry and did not cover all aspects of productivity management. There are therefore limitations in the present research. These include the following:

- Population of study: In this research the population was defined by membership of SAICE and SAFCEC. The individual responses did not give an indication of the respondents' designation, e.g. project manager. Further research is required that will include a section where the respondents identify their designations. By obtaining this information, the responses between the different designations (at various management levels) can be compared, and it will also indicate if there is an overall

Table 7 Comparison between the benchmark and the findings of the questionnaire (top ten ranked factors)

\begin{tabular}{|c|c|c|c|c|c|}
\hline \multirow{2}{*}{ Ranking } & \multicolumn{2}{|c|}{ Literature benchmark } & \multicolumn{2}{|c|}{ From questionnaire based on Rii (impact) } & \multirow{2}{*}{$\begin{array}{c}\text { Variance } \\
(\mathrm{A}-\mathrm{B}) \\
\text { ranking }\end{array}$} \\
\hline & Factor (A) & Category & Factor (B) & Category & \\
\hline 1 & Material shortage & Management & Late issue of drawings to contractor & Consultant & NA \\
\hline 2 & Labour experience & Labour & Illegal strike action by project labour force & Labour & -6 \\
\hline 3 & Incompetent supervisor & Management & Delayed reply on RFI (request for information) & Consultant & -7 \\
\hline 4 & Method of working & Management & $\begin{array}{l}\text { Late issue of specifications/information to } \\
\text { contractor }\end{array}$ & Consultant & NA \\
\hline 5 & Late issue of drawings & Consultant & Civil unrest in vicinity of project & Labour & +4 \\
\hline 6 & Poor communication & Management & Labour union strike (irrespective of union) & Labour & NA \\
\hline 7 & Unforeseen events & Management & Delayed inspection by consultant & Consultant & NA \\
\hline 8 & Poor site layout & Management & $\begin{array}{l}\text { Skill level of labour that is sourced in the } \\
\text { vicinity of the project }\end{array}$ & Labour & NA \\
\hline 9 & Constructability & Consultant & Complexity of design (constructability) & Consultant & 0 \\
\hline 10 & Rework & Management & Management skills of foreman & Management & NA \\
\hline
\end{tabular}


agreement or a discrepancy between the opinions and experiences of different management levels.

- Industry: The research only focused on contractors active within the civil construction industry. The opinions of consulting engineers were not considered in this study, and further research is required to obtain their opinions and to compare these with those of contractors. The expected end result will prove convergence or divergence of the opinions of both contractor and consultant.

- Factors: The factors that were selected for the questionnaire were obtained through a literature study, but did not include a review of these factors by the respondents or industry professionals. The approach that should be adopted in future research should include a review by the population to verify if the factors are relevant to the South African civil construction industry. The respondents in the population could also identify other factors that are not on the list of factors that they have reviewed.

\section{- Engineering Council of South Africa}

(ECSA): Two institutions were contacted to assist with the distribution of the questionnaire (SAICE and SAFCEC). For further research it is suggested that ECSA be contacted to assist with the research. This could also lead to productivity studies in other engineering fields, such as electrical and mechanical engineering.

- Stage-wise ranking: The study only considered the factors during the construction phase of the project. Further research should be done which identifies the factors during the design phase of a project. Furthermore, the design and construction phases should further be broken down into sub-phases, e.g. site start-up, mobilisation, execution, completion and handover.

\section{CONCLUSION}

The literature study clearly proved that the construction industry is faced with a fluctuating environment and tough economic conditions. This industry also plays an important part in the growth of the economy of a country. Moreover, the productivity of a country has an impact on the standard of living of its citizens. From this it is clear that the long-term sustainability of the civil construction industry and the sustainable growth of a country can be achieved by improving productivity.

A global perspective of the factors that have an impact was obtained, and it indicated that the construction industry in each country is unique in terms of the factors that have an impact on construction productivity. Furthermore, three categories of factors were identified that occur in the industry. They are management, labour and consultantrelated factors. The results of the questionnaire in this research produced a similar outcome. However, the consultant-related factors were the most highly ranked factors that have a perceived impact on construction productivity. This has led the authors to believe that the management framework should be customised to suit the industry within a specific country. In addition, the factors that were identified should form the basis of the management framework, in that the main focus should be on managing the said factors, although it is also important to incorporate other factors, even though they do not have an immediate impact on productivity.

\section{REFERENCES}

Abdul Kadir, M R, Lee, W P, Jaafar, M S, Sapuan, S M \& Ali, A A 2005. Factors affecting construction labour productivity for Malaysian residential projects. Structural Survey, 23(1): 42-54.

Alinaitwe, H M, Mwakali, J A \& Hansson, B 2007. Factors affecting the productivity of building craftsmen - studies of Uganda. Journal of Civil Engineering and Management, 13(3): 169-176.

Arditi, D 1985. Construction productivity improvement. Journal of Construction Engineering and Management, 111(1): 1-14.

Cloete, K 2013. Engineering skills shortage hampering growth. Engineering News, 20 August.

Department of Labour 2013. Annual Industrial Action Report 2013, pp 1-14.

Duryev, S \& Mbachu, J 2011. On-site labour productivity of New Zealand construction industry: Key constraints and improvement measures. Construction Economics and Building, 11(3): 18-33.

El-Gohary, K M \& Aziz, R 2014. Factors influencing construction labor productivity in Egypt. Journal of Management in Engineering, 30(1): 1-9.

Enshassi, A, Mohamed, S, Mustafa, Z A \& Mayer, P E 2007. Factors affecting labour productivity in building projects in the Gaza Strip. Journal of Civil Engineering and Management, XIII(4): 245-254.

Horner, R M W, Talhouni, B T \& Thomas, H R 1989. Preliminary results of a major labour productivity monitoring programme. Paper presented at the 3rd Yugoslav Symposium on Construction Management. Dubrovnik, Croatia.

Hughes, R \& Thorpe, D 2014. A review of enabling factors in construction industry productivity in an Australian environment. Construction Innovation, 14(2): 210-228.

Jarkas, A \& Bitar, C 2012. Factors affecting construction labor productivity in Kuwait. Journal of Construction Engineering and Management, 138(7): 811-820.

Kaming, P F, Olomolaiye, P O, Holt, G D \& Harris, F C 1997. Factors influencing craftsmen's productivity in Indonesia. International Journal of Project Management, 15(1): 21-30.

Kim, T, Lee, H-S, Park, M \& Yu, J-H 2011. Productivity management methodology using productivity achievement ratio. KSCE Journal of Civil Engineering, 15(1): 23-31.

Langston, C 2012. Comparing international construction performance. Mirvac School of Sustainable Development, Paper 150. Available at: http://www.epublications.bond.edu.au/ sustainable_development/150

Lim, E C \& Alum, J 1995. Construction productivity: Issues encountered by contractors in Singapore.

International Journal of Project Management, 13(1): 51-58.

Liou, F \& Borcherding, J 1986. Work sampling can predict unit rate productivity. Journal of Construction Engineering and Management, 112(1): 90-103.

Liu, M, Ballard, G \& Ibbs, W 2011. Work flow variation and labor productivity: Case study. Journal of Management in Engineering, 27(4): 236-242.

Makulsawatudom, A, Emsley, M \& Sinthawanarong, K 2004. Critical factors influencing construction productivity in Thailand. The Journal of King Mongkut's University of Technology North Bangkok, 14(3): 1-6.

Naicker, K 2014. SA labour productivity at its lowest in 46 years. Available at: http:// www.unisa.ac.za/news/index.php/2014/01/ sa-labour-productivity-at-its-lowest-in-46-years/

Odendaal, N 2014. SA one of the world's most violent, strike-prone countries. Available at: http://www. miningweekly.com/article/sa-one-of-the-worldsmost-violent-strike-prone-countries-2014-08-06 ONS (Office for National Statistics) 2007. The ONS Productivity Handbook: A Statistical Overview and Guide. Basingstoke, UK: Palgrave Macmillan.

Othman, A A E, Hassan, T M \& Pasquire, C L 2005. Analysis of factors that drive brief development in construction. Engineering, Construction and Architectural Management, 12(1): 69-87.

Oxford English Dictionary 2014. s.v. "management"; "productivity". Oxford University Press.

Republic of South Africa 2014. Government Gazette, 459 (37716), 3 June 2014. Government Printing Works.

Salem, O \& Zimmer, E 2005. Application of lean manufacturing principles to construction. Lean Construction Journal, 2(2): 51-54.

SAFCEC (South African Forum of Civil Engineering Contractors) 2014. State of the South African Civil Industry 2nd Quarter 2014. Johannesburg: SAFCEC. Zakeri, M, Olomolaiye, P O, Holt, G D \& Harris, F C 1996. A survey of constraints on Iranian construction operatives' productivity. Construction Management and Economics, 14(5): 417-426. 